\title{
THE OVERVIEW OF MAMMOGRAPHY SERVICE: ROLE OF INNOVATION AND SERVICE BLUEPRINTING
}

\author{
Daniella Cynthia Sampepajung, SE, MSc
}

Universitas Kristen Indonesia Paulus, Jl. Perintis Kemerdekaan Km. 13, info@ukipaulus.ac.id

\begin{abstract}
Controlling implementation of early detection and treatment of breast cancer is exigent as the disease is the most widespread type of cancer in the world. Mammography screening is one of the dominant technologies applied to achieve this purpose. It detects breast cancer through prevention route and symptomatic route.

This research focuses on service innovation perspective in developed and developing countries, which are the cases of the United Kingdom and Indonesia respectively. The United Kingdom implements both prevention and symptomatic routes to control the disease, while Indonesia as this research was written implements the symptomatic route. Furthermore, it investigates the evolution of mammography service in both countries and how they comply with path dependency and lock-in theory.

There are two significant roles of innovation discovered: process innovation in digital mammography and service innovation in mobile mammography. Service blueprinting is used as a framework to investigate the possible methods to improve the service as well as to determine the possible failure points in the two cases. Furthermore, this research found out that blueprint could be used as a quality mechanism. In addition, it is discovered that the difference in organization size from both cases produces a significant impact on the number of service actions delivered, such as Quality Assurance implementation, cultural barrier, and financial challenge. Although this research does not introduce a comprehensive assessment of mammography service in the UK and Indonesia, it offers empirical evidence which will enrich the study of mammography service.
\end{abstract}

Keyword: innovation; service innovation; lock-in theory 


\section{Introduction}

Breast cancer is the third leading cause of cancer deaths in the United Kingdom (Cancer Research UK, 2012) and second in Indonesia (Depkes, 2009). It is vital to discover new methods to prevent and manage the disease. Early detection and treatment are important to reduce the cancer mortality. There are several major technologies used in the early detection of breast cancer, one of which is mammography screening.

As the number of breast cancer patients increases, it is very important to have health services which aim to prevent this disease. Breast cancer, in most cases, is more treatable than other types of cancer. It has a higher chance to heal by detecting the cancer cell in early stages before the tumor cell becomes invasive. In order to achieve this, an effective breast screening programme is implemented and mammography screening technology is used as one of an essential tool (Forrest, 1986).

The United Kingdom is the first country in the world to establish a national scale breast screening program (Forrest, 1986). Cancer Research UK (2012) has reported that the survival rate of breast cancer in the UK in 2007 was over $70 \%$. This is much higher compared to the $40 \%$ survival rate in Indonesia (Pfizer, 2008). NHS claimed that the high survival rate is due to the fact that there is a comprehensive breast screening programme (NHSCSP, 2008).

This paper aims to investigate three questions: how has mammography service been evolving; what is the role of innovation in mammography service; and what are the challenges, potential, and barriers to the mammography service.

\section{Literature Review}

\subsection{The Path Dependency of Mammography}

Historical background has an important role in understanding the process of technological lock-in. Path dependency can be described as a series of incidents that consequently established a certain technology to be widely deployed in the market and become the dominant design. In the journey of treating breast cancer, mammography technology has become the preferred technology to do early detection of the disease (Forrest, 1986; Van Steen \& Van Tiggelen, 2007; Nelson et al., 2004). Hence, mammography became the dominant technology to detect breast cancer.

Van Steen and Van Tiggelen (2007) describe the evolution of mammography in three periods. The first occurred during 1913 to 1940 , when radiography technology was in its initial exploration as a tool to diagnose breast abnormalities. Afterwards, during 1940-1970, as it was researched and developed extensively. The third period presents the last quarter of the $20^{\text {th }}$ century, in which the mammography technology 
has been developed vastly and deployed globally.

Nelson et al., (2004) stated that mammography was adopted widely and became the dominant design. The reason was that institutions, which in this case were mostly radiologists and oncologists, were convinced that mammography was the best option. The study suggests that there are four models of the adoption of an innovation: rational choice, quasi-rational choice with the possibility of lock-in, social construction, and fads (Nelson et al., 2004).

The adoption of technology from one country to another can be explained by a leapfrogging concept (Goldemberg, 1998). It is a concept of sustainable development for developing countries in order to escalate by skipping inferior, less efficient, more expensive technologies and industries and switch directly to more advanced ones. The concept of leapfrogging is about jumping technological generations. Munasinghe (1999) adds that developing countries could learn from the experiences of developed nations, as well as restructuring growth and development.

\subsection{Mammography as a Service}

In the past couple of decades, service innovation has grown rapidly. The technology of mammography is implemented in health care systems, in hospitals as well as. Mammography itself is a service, concluded by the fact that it is carried in a service environment. For the purpose of this research, the use of mammography technology both in the national breast screening programme and the symptomatic pathway is described as mammography service.

The healthcare service is a complex system that includes physicians of all sorts of medical specializations that continuously conduct integrated health care process, i.e. diagnose, the decision on treatment, coordinating with technical and administrations sections and so on (Donaldson et al., 1996; Neslin, 1983). Furthermore, the complexity of health service also depended on the size of the organizations and the number of types of health service they deliver.

\subsection{Service Blueprint}

Service blueprinting is a tool to manage the obstacles of conducting service process and analysis (Brown et al., 1991; Bitner et al., 2008; Shostack, 1984). Outlining a service at a different level of analysis and identifying steps in the whole process can be done with service blueprinting. The aim of service blueprint is to generate a comprehensive overview of the entire course, which would assist the service providers to assess their service processes and improve the quality.

Bitner et al., (2008) generate five basic elements of service blueprint with the aid of 
the suggestion as follows: Customer actions; Onstage/visible contact employee actions; Backstage/invisible contact employee actions; Support processes; and Physical evidence. The process of service blueprint is: identifying process, isolating fail points, establishing timeframe, and analyzing profitability.

Dodendorf et al., (2004) developed a blueprint of the mammography service in the USA. The blueprint shown in Figure 1 maps out the experience of the patient in making a mammography appointment until the last stage, which is getting the result. The blueprint includes patient action area, onstage area, backstage area, and support process area.

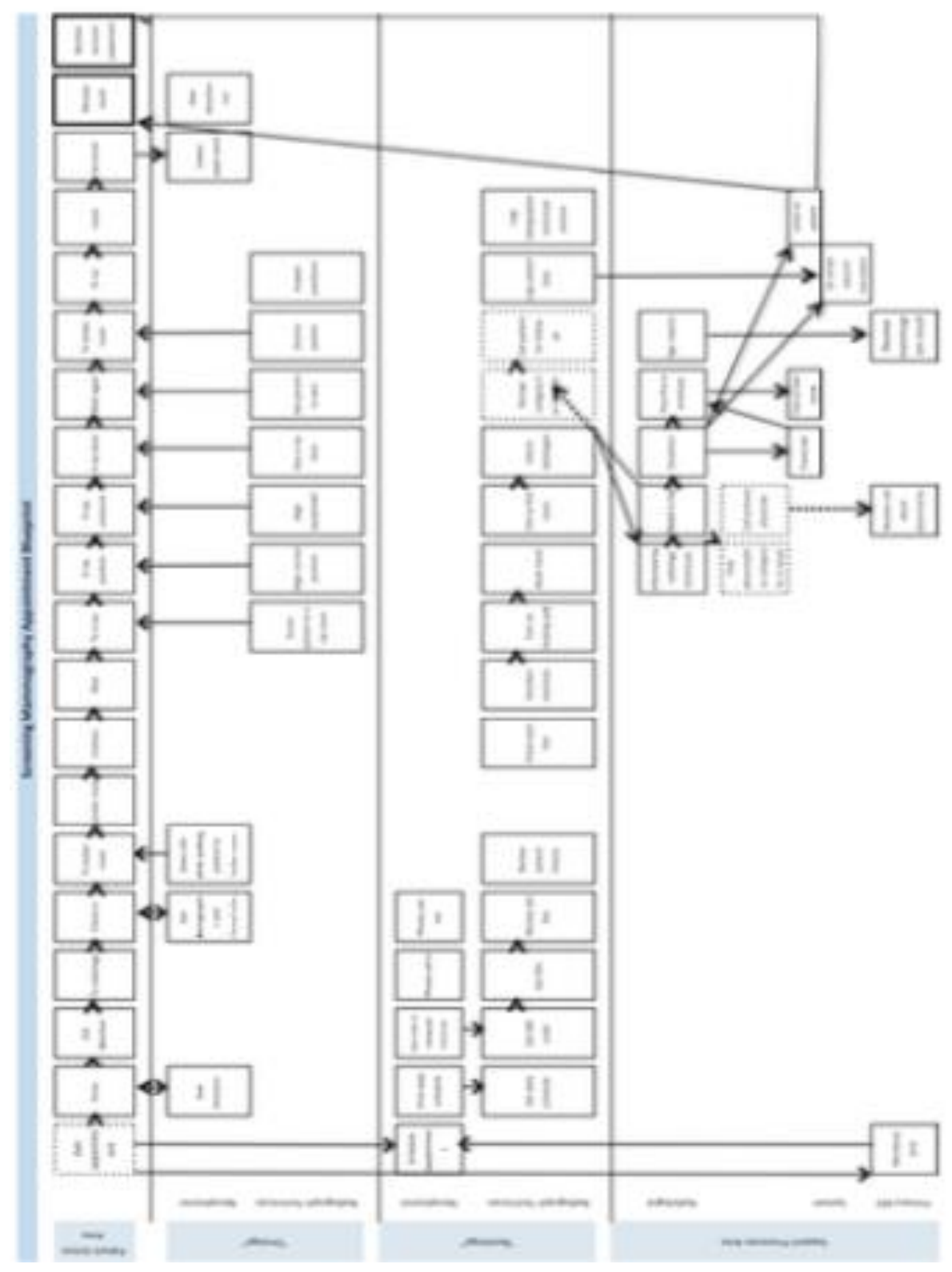

Figure 1 Screening Mammography Appointment Blueprint. Source: Dodendorf et al (2004)

Creating blueprint requires several methods for data collection such as patient 
scripts, patient pathways, field notes, paper/electronic trails of referral, diagnosis, test results and communication, and chart audits. The process of collecting the data is quite long and expensive because it requires several people to collect the data. Even though the collecting process is not difficult, it is time-consuming (Dodendorf et al., 2004). The implication is that different mammography service facilities may have very different service processes especially in the settings of different countries.

\section{Methods}

This research uses a case study in two organizations in the United Kingdom and Indonesia. For the UK the organization is the National Health Service Breast Screening Programme (NHSBSP), namely the Breast Unit of Royal Bolton Hospital $(\mathrm{RBH})$, Lancashire and Wythenshawe Hospital, South Manchester. The organization in Indonesia is Prima Laboratory, Surabaya, Indonesia. All organizations included in this research conduct mammography service.

Two instruments are applied to collect empirical evidence: in-depth interviews and secondary data. Bitner's (2008) service blueprint format is used as the framework of the service processes. The relevant people interviewed in this research are the decision makers are breast screening directors of NHSBPS, a member of QARC team, and the owner of Prima Laboratory, as well as the people who perform the service, which is the radiologists and radiographers. The secondary data used are websites of NHS Cancer Screening, WHO, and of Indonesian Ministry of Health Republic.

There are several limitations to be taken into account. First of all, the research is limited to a three-month period, which also affects the number of interviewees hence may restrict the viewpoints. Furthermore, one of the cases investigated in this study is located in a single mammography service in Surabaya, Indonesia. Therefore, the service design and quality assurance implementation may not be generalized. However, studying a single case in the country has allowed this study to investigate the themes and issues in greater detail.

\section{Findings}

\subsection{The Evolution of Breast Screening}

\subsubsection{The NHSBSP of the UK}

The interviews reveal that the breast screening programme in the UK started with the "Forrest Report" in 1986. The report was based on the findings of two large studies in Sweden and in the USA. It played a very significant role in determining the establishment of the UK's advanced breast screening programme (NHSBSP).

The general consensus of the only way to increase the survival rate of breast cancer was to detect it before the patient came with symptoms. At the time, no country had 
yet established a successful national breast cancer screening programme (Forrest, 1986). There were a few screening facilities for ladies with lumps that led to symptoms (Wilson, interview, 05/07/12). However, in order to develop a mass population screening programme, the report assesses 'screening' on women who appear healthy in order to detect unrecognized breast cancer. As a result of the Forrest Report, NHSBSP was established in March 1987 and started inviting women in 1988 (NHSCSP, 2008). Today the program has succeeded to detect over 100,000 cancer cases since the program started. NHS (2008) reported having reduced mortality from breast cancer of about $35 \%$ for women who are screened regularly.

There are two routes for detecting breast cancer in the UK (Boggis, interview, 10/07/12; Wilson, interview, 05/07/12; NHSCSP, 2012; Breakthrough Breast Cancer, 2011; NHS Health Unlocked, 2010; NHSBSP, 2008). First, a woman (although there is also a possibility of male breast cancer) finds a lump. She would then check with her general practitioner (GP), who would refer her to a clinic for a further investigation that includes a mammogram taken on her. This is called the symptomatic pathway.

The second pathway is detecting breast cancer through the NHSBSP. In this scheme, a woman will get an invitation for a mammogram between her $50^{\text {th }}-53^{\text {rd }}$ birthday, sent by her local NHSBSP (Breakthrough Breast Cancer, 2011). This is the preventive route that is conducted on mass population. Originally the screening was done in women age 50-70. Younger women do not get invitations to the screening because studies show that the strongest risk factor for breast cancer (after gender) is age: as women get older, the risk gets higher (Cancer Research UK, 2008). However, the Department of Health's Cancer Reform Strategy has announced that from 2012 the NHSBSP will do age expansion of the invitation that covers women between the ages of 47 and 73 (NHSBSP, 2010). Currently, the breast unit of Royal Bolton Hospital and Wythenshawe Hospital is undergoing the implementation of the age expansion plan (Maxwell, interview, 02/07/12; Wilson, 05/07/12). Nationally, the programme is expected to fully run by 2016 (NHSCSP, 2012).

\subsubsection{Detecting Breast Cancer in Indonesia}

Indonesia is a developing country with limited resources that implement early diagnosis programmes, according to WHO (2012) categorization. Nationally, there are no breast screening programmes available in the country (Tango, interview, 16/06/12; Mardiyana, interview, 16/07/12). Radiologist, Dr. Lies Mardiyana from East Java Regional Hospital explained that the reason is that the Government is still focusing on cervical cancer, the number one death cancer cause in the country, rather than breast cancer (Mardiyana, interview, 16/07/12).

In 2007, the Health Department of Indonesia started a cancer management programme using Clinical Breast Examination (CBE) (Depkes, 2009) which is a physical examination done by health professionals. The CBE does not necessarily involve mammogram; breast screening using the technology is only conducted if there are any lumps found in the CBE. This early diagnosis programme has been carried out in 17 out of 33 provinces of Indonesia. 


\subsection{Quality Assurance}

The interviews with the directors of Breast Screening in Wythenshawe Hospital and Royal Bolton Hospital highlight that quality assurance is very important in running a breast screening programme. Each unit strictly follows the national guidelines in terms of the exact pathway of running a mammography process. When the NHSBSP was established, it came with a numerous pile of Quality Assurance (QA) around it. Therefore, all the machines are required to pass a certain physics test and need regular checks.

According to Prof. Boggis (interview, 10/07/12), the Quality Assurance Reference Centre (QARC) closely monitors the NHSBSP units. The QA has been embedded deeply in the NHSBSP system. The main aim of quality assurance in the programme is to maintain minimum standards and enhance performance in all aspects in order to guarantee that all women across the country have access to a high-quality breast screening service (QARC, 2010; NHSBSP, 2012).

In Indonesia, QA is enforced by Direktorat Jenderal Kefarmasian dan Alat Kesehatan (Pharmacy and Health Equipment Directorate General), which is part of the Indonesian Ministry of Health.

\subsection{The Role of Innovation in Mammography Service}

The interviews highlighted two types of innovation involved in the mammography service. Based on Schumpeter's definition of innovation, the innovations related in this case can be classified into two groups: process innovation and service innovation.

The growth of knowledge in the medical innovation process is punctuated by specialization, diversification, and coordination (Consoli et al., 2009). Technology developments are presented mostly in conferences or medical publications. For example, a mammography innovation first introduced in the US can later be implemented in other countries (Starfield, 1998; Barger-Lux \& Heaney, 1986).

\subsubsection{Process Innovation in Mammography Service}

Mammography is a technology in the radiology field of science. The conventional mammography uses X-ray film to capture images of breast tissue while digital mammography uses computer imaging. NHSCSP (2012) announced that 85 percent of breast screening units in the programme have had a minimum of one digital mammography set since July 2011. Maxwell (interview, 02/07/12) also mentioned that the Breast Unit of the RBH has been fully digitized since the beginning of 2012 .

The Digital Mammographic Imaging Screening Trial (MST) has demonstrated that screening of younger women and women with denser breast tissue is better with 
digital mammography (DMIST, 2005). However, digital mammography is as effective as film- screen mammography for older women. Along with the evidence that older women collectively have a higher risk of having breast cancer, this finding means digital mammography is still being used in the breast screening programme for older women.

The NHS Cancer Screening Programme periodically assesses the equipment that the programme is currently and will be using. This is implied by Prof. Boggis (interview, 10/07/12) and is shown in the NHSBSP Publications of Mammography Equipment (NHSBSP, 2012). NHS Supply Chain, the national purchasing, and logistics organization arranges a national framework protocol for medical imaging and diagnostic equipment that includes digital mammography from 2007. Barr et al., (2010) suggests that the advantage of digital mammography is able to repeat inadequate mammograms without recalling the woman.

Mary Wilson, Breast Screening Director of University Hospital of South Manchester (UHSM) stated that the NHSBSP has moved to digital radiography and PACS (NHSBSP, 2007). The system is used to manage the documentation and communication within screening facilities and hospitals. PACS allow images such as $\mathrm{X}$-rays and scans to be saved electronically and observed on screens, enabling a near filmless process and enhanced diagnosis methods. The system allows radiologists and radiographers to access and compare images very easily (NHS, 2012).

\subsubsection{Service Innovation in Mammography Service}

Dr. Maxwell of Royal Bolton Hospital explains that innovations in new processes in the service since the first establishment of the programme include: the age expansion programme; training radiographers to read mammograms as a result of radiologist shortage; and mobile mammography.

The initial age range of women invited every three years for cancer screening is between the age ranges 50-70 (NHSBSP, 2011). However, in 2007, it was decided to extend the age range from 47-73. This change resulted in the increase of screening appointments of approximately $15 \%$. The age extension means offering to screen to 400,000 women each year, which is an innovation in service.

Mobile mammography is part of the NHSBSP, which alongside static sites, used to utilize film-screen mammography and now has converted to digital ones. However, in order to read the screening results, the images have to be transported to its breast screening units.

The Breast Unit at Royal Bolton Hospital (RBH) screens approximately 26,000 women every year, using both static and mobile mammography. Meanwhile, UHSM screens approximately 42,000 women every year and runs four mobile units. Mobile mammography units are placed on public sites such as supermarkets or parks. The trailers have digital mammography installed but they strictly serve women by invitation only (NHSCSP, 2012). 


\subsection{Blueprint in Mammography Services}

World Health Organisation (WHO, 2012) categorizes efforts of the early detection of cancer into two parts: early diagnosis and screening.

The national breast screening programme (NHSBSP) uses the pathway approach in mapping its service process, as seen in the QA Guidelines. Below is an overview of service blueprinting in NHSBSP, based on information gathered from the interviews and NHSBSP QA for Administrative and Clerical Staff (NHSBSP, 2000).

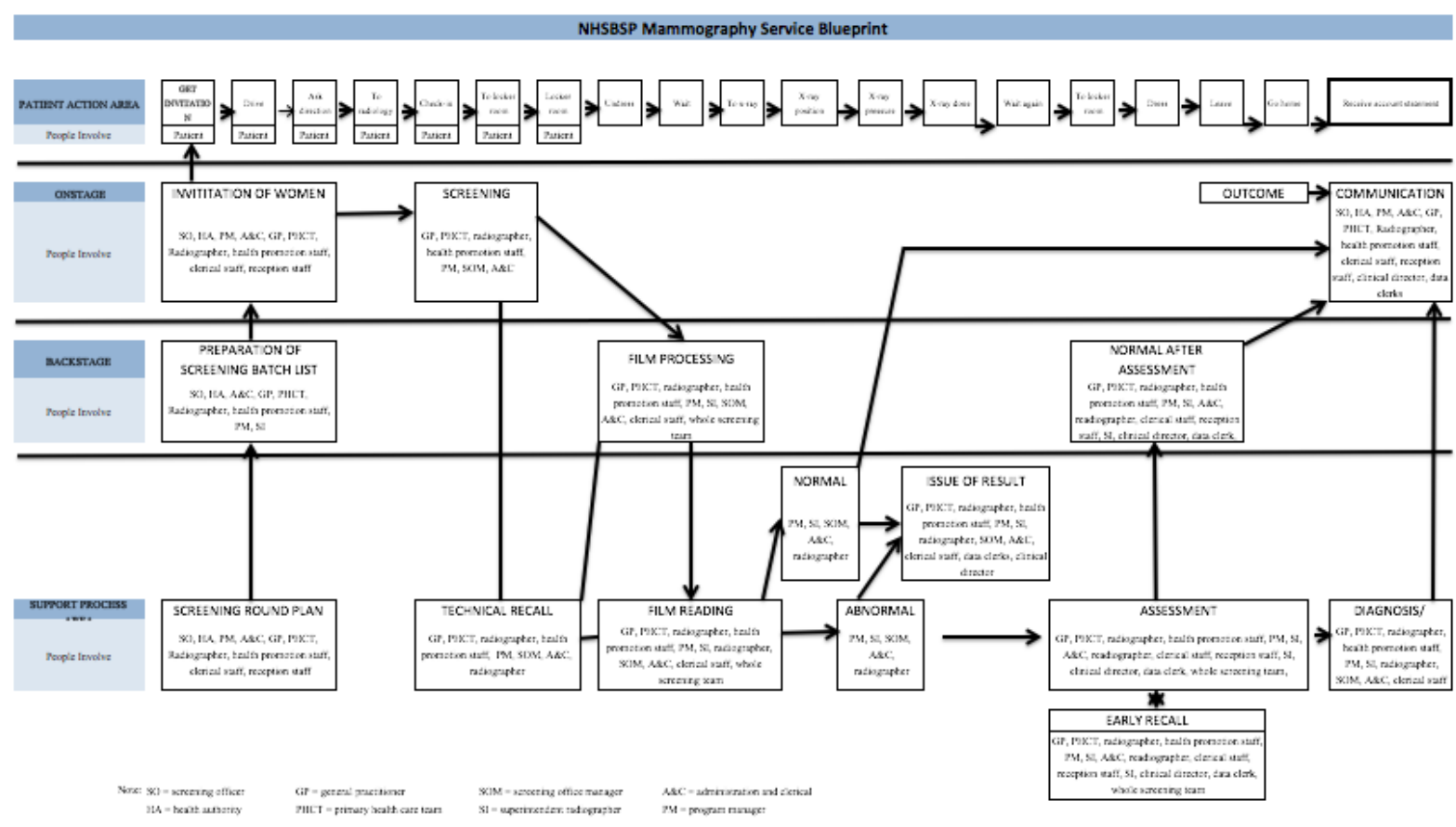

Figure 2 - NHSBSP Mammography Service Blueprint. Source: NHSBSP (2000)

As the previous section has explained, there is no mass-population screening programme in Indonesia at the moment. However, there are many breast screening services available both in government-funded hospitals and private hospitals as well as diagnostic laboratories. Most of the breast screening facilities are located in the major cities and run on a symptomatic basis, which means the patient gets to use the mammography service after being referred for one.

The interviews with the radiographers and radiologists of the radiology department in the Prima Laboratory confirms the following blueprint of their mammography service. 


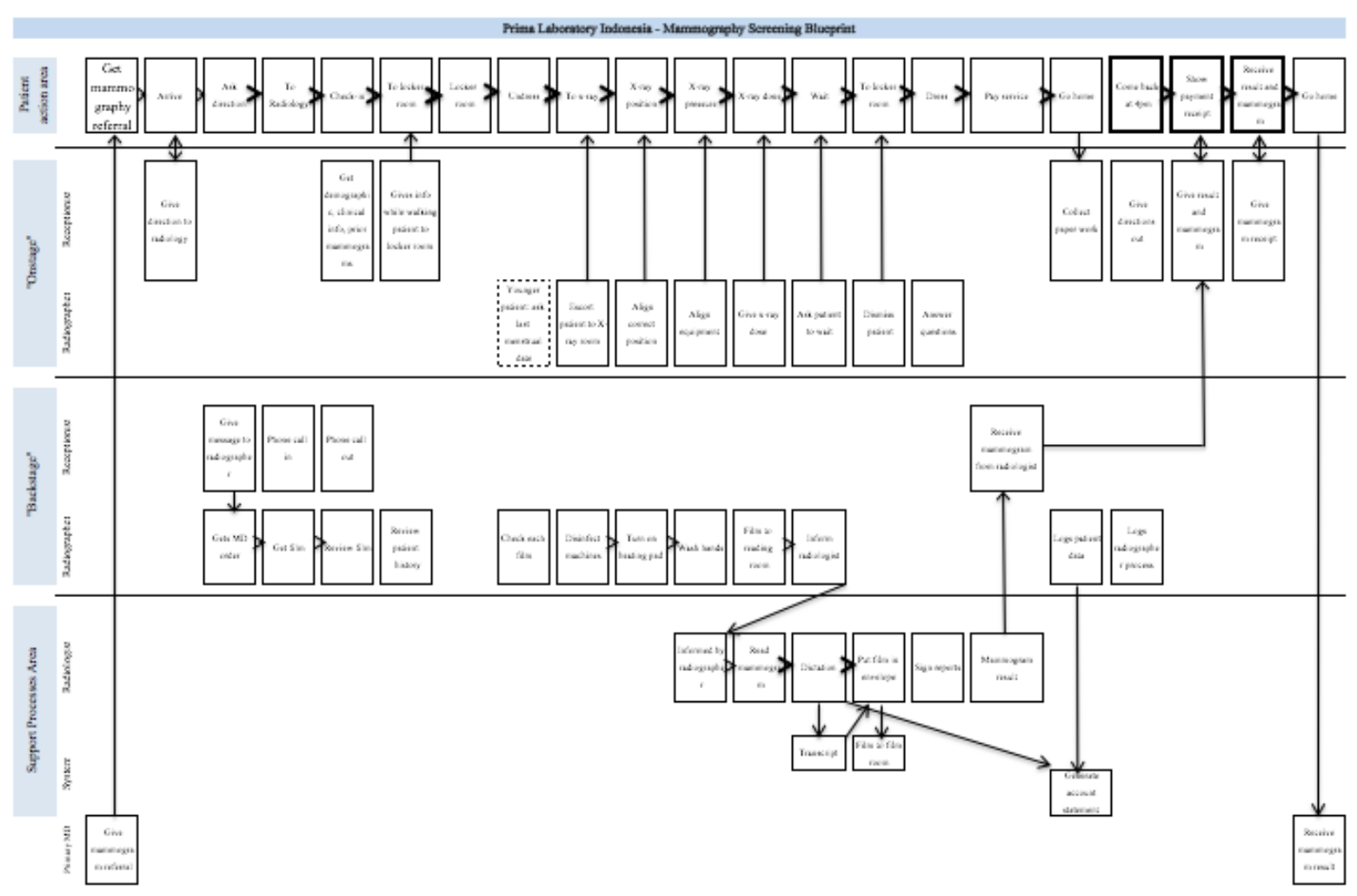

Figure 3 - Prima Laboratory Mammography Service Blueprint. Source: Author (2012)

The blueprint of Prima Laboratory details the actions conducted in the whole service process. There are the actions customers have to go through, actions of receptionists, radiographer, radiologist, and the primary physician. In most cases in Indonesia, the primary physician is an oncologist (Mardiyana, interview, 16/07/12). This is different with the UK, in which the primary physician could be a general practitioner of the patient because in Indonesia most patients come for mammography service after they find a lump. In the case of the UK, most women come for by the NHSBSP invitation. If there aren't any abnormalities, there is no need to involve oncologists.

\section{Discussion and analysis}

\subsection{Path Dependency}

The interviews and secondary research show that the UK has documented its mammography service thoroughly. Even though there is not yet a scholarly document that covers the history of mammography service in the UK, there are publications that describe the milestones of the service development.

"Mammography is very good because it's cheap, easy to use, and accurate", stated Professor Boggis, a senior radiologist in UHSM and also a member of QA team of NHSBSP. She further compared mammography to Magnetic Resonance Imaging 
(MRI) and explained that as technology developed, NHS professionals have found that mammography is much more efficient than MRI. For example, a mammogram takes approximately 15 minutes to be conducted while an MRI machine takes an hour. In addition, MRI is also highly sensitive but unspecific.

Being the dominant design to prevent breast cancer, mammography assists to manage the service on a large scale if not globally. Lock-in of a technology ensures uniformity of modern health care implementation, which the comprehensive QA system is based on. The dominant design of technology enforced uniformity in modern healthcare, which later affected the comprehensive QA implementation to bring consistent service quality at all times.

In conclusion, the path dependency of mammography began with the study in Sweden and the USA and later recommended in the Forrest Report. There were other technologies considered as well, such as ultrasound and MRI. However, when the UK as the first country to have national breast screening programme decided to choose mammography as the best option, the mammography was developed intensively and improved. Hence the mammography received increasing returns and became the dominant technology to do early detection of breast cancer. In addition, mammography is also utilized as a preferred technology for symptomatic screening due to its efficiency and cost (Lord et al., 2007; Boggis, interview, 10/07/12).

\subsection{Process Innovation in Mammography Service}

The health care system is also subject to Schumpeter's innovation concept. All five innovations can be identified in the health care system. A health service provider adopts new medical machinery, uses new kinds of materials for its utensils, expands to new market specialization that exclusively serves women, applies new processes to deliver its services, and implements new ways to manage its organization. This research focuses on two aspects of innovation related to the research questions: process innovation and service innovation in mammography service. Nelson et al., (2004) proposed a framework of four models of the adoption of an innovation: rational choice, quasi-rational choice with the possibility of lock-in, social construction, and fads.

The current major process innovation in mammography service is the introduction of digital mammography. Today, instead of using analog technology to create the image, digital technology is employed. The Department of Health Advisory Committee on Breast Cancer Screening conducts studies to assess which technology, direct digital radiography or computerized radiography, is more suitable for the programme. The result of the study was applied to direct digital radiography. Afterwards, NHSBSP started purchasing and implementing digital mammography machines from July 2011.

Nelson et al. (2004) argue that the adoption of mammography technology is socially constructed because it involves many arguments about its advantages and disadvantages. However, the decision of implementing direct digital mammography is based on numerous research studies that recommend the new technology. Digital mammography's merit is established with solid evidence. For that reason, the 
diffusion of digital mammography throughout the whole NHSBP is a rational choice.

\subsection{Service Innovation in Mammography Service}

One important service innovation found in this research is mobile mammography. Mobile mammography uses the same technology as the static screening unit, the difference is the mammography machines are placed in a van and located in public places. This innovation is meant to enable patients in remote and larger areas to get access to breast screening. More compact areas, such as Bolton, do not offer mobile mammography services. Larger geographical areas, Wales, for example, need mobile mammography more (Maxwell, interview, 02/07/12).

The mammography process in mobile or static mammography sites is essentially the same. The blueprint would be different since mobile mammography sites need to transport the mammogram result to its center unit for reading, but the pathway of major actions in the service remains the same. Using the information gathered from both primary and secondary research, all breast screening activities in conducting a mammography service are identified. Due to the size difference of the organizations researched, the activities are categorized into four major actions. The first major activity in mammography service is getting the patient to get mammography, which is screening invitation NHSBSP, and patient registration or referral from a primary physician in Prima Laboratory. The second big activity is getting the mammogram using the mammography machine. Afterwards is the process of reading the mammogram result by a radiologist, which also includes other staff indirectly. The final big activity is communicating the mammogram result to the patient.

\subsubsection{Mammography Service Blueprint}

In order to see the applications of service blueprinting, this research has mapped out a blueprint overview of NHSBSP to understand the establishment of the UK and Prima Laboratory for Indonesia as shown in Figure 1 and Figure 2 in the previous section.

Both blueprints show that the size of the organization may have implications as to the service actions. Each breast screening unit of NHSBSP has to act in accordance with the QA, no matter the location of the units. The NHSBSP blueprint displays that each activity in the NHBSP process relates to multiple sections or staff or the organization. For instance, the film screening action concerns nine different sections. Only the radiographer has the direct responsibility of conducting the screening, which is operating the mammography machine and positioning the patient to the machine accordingly. But, the other sections have indirect responsibility for this action. GP, PHCT (primary health care team), health promotion staff, superintendent radiographer $(\mathrm{SI})$, program manager $(\mathrm{PM}), \mathrm{SOM}$ (screening office manager), $\mathrm{A} \& \mathrm{C}$ (administration and clerical), clerical staff, and the whole screening team have the indirect responsibility to ensure communication and documentation of the film screening action runs smoothly. 
In comparison, a film screening in Prima Laboratory only concerns the radiographer directly. In this particular action, the radiographer's responsibility is the same as the one in the NHSBP process. However, only the receptionist and radiographer are responsible for communicating the film screening action to the patient and only the radiographer does the storage of the result.

Blueprints provide an overview of detailed actions included in a service process. The fail points show the possible mistakes that may happen and the likeliness. Hence the blueprints and table of fail points are used as a tool to perceive the entire course comprehensively and help service providers assess their service processes and improve quality. Consequently, the cases confirm the studies of Shostack, Bitner, and Brown.

People who find service blueprints useful are not limited to the decision makers only. Blueprints, arguably, can also be used for staff in lower management or front liners to understand the organizations they work in as a whole. The line of actions and correlations between them give guidance for staff to understand the impact of what they are doing, what other actions may be affected, the relations between actions, whose course of actions affect them and which responsibilities they may have an influence on. Even the most uncomplicated action may affect other actions, let alone the more complicated ones. For example, if a receptionist is not present to receive patients when they arrive, radiographers might have to receive patients instead thus delaying them in conducting the mammography screening and therefore affecting other patients. The impacts could lead to significant work inefficiency. This problem could be resolved easily by ensuring there is another receptionist to substitute.

Benzel et al., (2009) identified that unavailability of prior mammogram results affected inefficiency and additional workups. Therefore, the study resolves to educate the staff responsible for scheduling to remind patients to bring their prior mammograms. Reminding patients to bring prior mammograms can be seen as an addition of one action detail in the scheduler's job. One action detail, it turns out, has the impact of increasing efficiency. By adding one additional action detail in the blueprint shows the relation between one action detail to other actions. In the case of NHSBP, reminding patients to bring prior mammograms is included in the fail points and included in the QA description. It belongs to screen round plan action course. Prima Laboratory also asks for prior mammograms in the onstage level, alongside getting demographic and clinical information.

The line of visibility, in particular, plays an essential role in designing service blueprint. It determines some of the central actions of the whole service process. Invisible and visible actions have to be designed carefully in order to maximise the desired effect on the customer (Shostack 1984, 1985). The line of visibility distinguishes onstage and backstage element of service blueprinting (Bitner, 2008). In addition, there are also actions which customers have done themselves and actions of the supporting staff that do not interact with customers specifically. 


\section{3. 2. Service Blueprinting and QA in Mammography Service}

The literature about service design since 1984 by Shostack to Quality Assurance by Ellis and Whittington (1993) suggests that modern customers are very well aware that they have the right to receive the best quality in their health service. The existence of government ruled authorities such as NHS Quality Assurance Reference Centre also proves that quality of service is being enforced in the UK.

To the contrary, the mammography service Laboratory does not have a set of QA protocols implemented. According to the owner (Ratna, interview, 07/07/12), this is due to the scale of its business. The Indonesian Department of Health does regulate the standards for hospitals, smaller clinics, and laboratories. However, smaller practices such as Prima Laboratory were only required to pass annual inspections (Depkes, 2009).

The case of Prima Laboratory might be considered as an anomaly since it deviates from the expected incorporation of QA. A senior radiologist of Prima Laboratory confirms that bigger hospitals implement prescribed Standard of Procedures (SOPS) as well as QA (Mardiyana, interview, 15/07/12). However, the service has run well for sixteen years without any major implications of not having QA protocols (Ratna, interview, 07/07/12).

The statement suggests that the management of Prima Laboratory does not consider having QA as urgent. Based on their experience there has not been any evidence of the need to set a standard QA. According to them, the patients are always satisfied and complaints are more often addressed to miscommunications rather than procedural mistakes. But then again, if they had implemented blueprints and QA, these miscommunications might have been avoided altogether.

In the UK, both symptomatic pathway and NHSBSP have very standardized and prescribed QA. Based on the interviews, it can be seen that QA provides very detailed guidance for the NHS BSP staff that helps them to deliver their service to the best quality according to the standards set. Nevertheless, it can be argued that a service blueprinting can provide a quick overview of the supposed service process. It can serve as an additional tool that provides a 'quick-look' at the whole service process.

The two differences are caused by scope difference, hence the gap in patient numbers. Prima Laboratory, with far less patient numbers, believe that its service is well delivered even without lengthy procedural regulations. The number of regulations can be related to strict authority monitoring. The standards NHS employs are strictly legally binding. In contrast, Prima Laboratory also applied standards set by the Ministry of Health. The difference is that the monitoring is not as strict and comprehensive. In addition, the owner acknowledges that QA is not yet considered as urgent. The important thing is to apply the ministry standards safely.

It can be concluded that the reason QA is enforced in one country and not in another is that of the legal bind. Since there is no urgency, it is not being enforced. 


\section{Conclusion}

\subsection{Recalling the Research}

This research aims to present the case of mammography service in the UK and Indonesia using the service innovation perspective.

How has mammography service been evolving? Breast cancer is a disease spreading globally, which initiates the UK to assess the best method to prevent and control it. The answer to this question is started by the Forrest Report in 1986 which recommended mammography technology as a vital tool to manage the disease. Path dependency of mammography began with the study in Sweden and the USA and later recommended in the Forrest Report. Superior results of mammography screening compared to other technologies such as ultrasound and MRI led to its technological lock-in. Hence, it is chosen as the technology used for early breast cancer detection in the NHS Breast Screening Program. The NHSBSP invites about 2.7 million women every year each of them is re-invited every three years. The program aims to conduct early detection of cancer cells, which would increase the chances of surviving the disease. In the future, it is possible for NHSBSP to invite women more frequently and conduct more targeted screening. In Indonesia, the current mammography service available is delivered on a symptomatic basis. The country is developing breast cancer management through Clinical Breast Examination scheme. However, the scheme doesn't utilize mammography service because it requires a huge amount of financial as well as human resources, which are still a challenge in Indonesia. In the case of Prima Laboratory, the service has been established for sixteen years. Two blueprints for both NHSBSP and Prima Laboratory have been developed in this research, showing the activities conducted throughout the mammography service process.

The study went on further by analyzing innovations utilized in mammography service, which reflected on the second research question - What is the role of innovation in mammography service? The answer to this question is the product and process innovation. A major product innovation is the utilization of digital mammography and in the process, innovation is mobile mammography. More importantly, this research attempts to implement service design and service blueprint which enhance the quality of mammography service. The actions involved in conducting mammography service are mapped out in service blueprints of NHSBSP and Prima Laboratory.

The final research question is what are the challenges, potential, and barriers to the mammography service? It seems that both countries face similar challenges in conducting the service. The research finds that the problems are cultural barriers, financial challenges, and both countries face staff shortages.

\subsection{Lessons Learnt}

The leapfrogging concept suggests that developing countries should omit inferior, less efficient, and more expensive technologies and move directly to more advanced ones (Goldemberg, 1998). Innovation may also apply in this concept. Indonesia can 
learn from the UK that breast cancer survival rates can be enhanced through a comprehensive national breast screening programme, such as exemplified by NHSBSP. In the future, should Indonesia have the resources to establish a national breast cancer early detection programme through breast screening, the country should also omit X-ray mammography and apply direct digital instead? Furthermore, it is learned that comprehensive QA and blueprint assure that service is delivered according to an established standard. Visibility lines and fail points enhance the performance of service and at the same time avoid possible mistakes.

Furthermore, it is found that organization size gives the significant implication of literature implementation. Organisation size affects $Q A$ implementation and the number of service actions. For example, QA is massively employed in NHSBP, which is a big national organization. Meanwhile, QA is not applied extensively in Prima Laboratory. Every level of the service provider from both organizations can benefit from using service blueprint as a quick overview of the supposed service process.

\section{References}

Barger-Lux, M.J. \& Heaney, R.P., 1986. For Better and Worse: The Technological Imperative in Health Care. Social Science Medicine, 22(12), pp.13131-1320.

Barr, N. et al., 2010. Comparison of Microcalcification Detection Rates and Recall Rates in Digital and Analogue Mammography. JWDM, LNCS(6136), pp.513-17.

Benzel, J.L. et al., 2009. Improving Mammography Screening. American Journal of Nursing, 109(11), pp.43-45.

Bitner, M.J., Ostrom, A.L. \& Morgan, F.N., 2008. Service Blueprinting: A Practical Technique for Service Innovation. California Management Review, 50(3), pp.66-93.

Brown, S.W., Gummesson, E., Edvardsson, B. \& Gustavsson, B., 1991. Service Quality - Multidisciplinary and Multinational Perspectives. New York: Lexington Books.

Cancer Research UK, 2008. Cancer Research UK. [Online] Available at: http://info.cancerresearchuk.org/cancerstats/types/breast/riskfactors/breast-cancerrisk-factors [Accessed 12 July 2012].

Cancer Research UK, 2012. Cancer incidence and mortality in the UK for the 20 most common cancers. [Online] Available at: http://publications.cancerresearchuk.org/cancerstats/statsincidence/reporttop20inc mort.html [Accessed 12 July 2012].

Consoli, D. et al., 2009. The Process of Health Care Innovation: Problem Sequences Systems, And Symbiosis. In The Economics of New Health Technology: incentives, organization, and financing. Oxford University Press. pp.19-39. 
Depkes, 2009. Ministry of the Health Republic of Indonesia. [Online] Available at http://www.depkes.go.id/index.php/berita/press-release/1060-jika-tidak-

dikendalikan-26-juta-orang-di-dunia-menderita-kanker-.html [Accessed 15 July 2012].

DMIST, 2005. Diagnostic Performance of Digital versus Film Mammography for Breast-Cancer Screening. The New England Journal of Medicine, 353(17), pp.177383. http://www.cancer.gov/cancertopics/factsheet/detection/mammograms [Accessed 17 July 2012].

Dodendorf, D.M., Deogun, G.K., Rodie, A.R., Pol, L.G, 2004.Assessing the Patient's Mammogram Experience. In Health Care Management Review. pp.77-87

Donaldson, M.S., Yordy, K.D., Lohr, K.N. \& Vanselow, N.A., 1996. Primary Care: America's Health in a New Era. Washington, D.C.: National Academy Press.

Ellis, R. \& Whittington, D., 1993. Quality Assurance in Health Care: a Handbook. London: Edward Arnold.

Forrest, S.P., 1986. Breast Cancer Screening. Report to the Health Ministers of England, Walse, Scotland, and Norhern Ireland. London: Her Majesty's Stationery Office Department of Health and Social Security.

Goldemberg, J., 1998. Leapfrog energy technologies. Energy Policy, 26(10):729742.

Lord, S.J. et al., 2007. A Systematic Review of The Effectiveness Of Magnetic Resonance Imaging (MRI) As An Addition To Mammography And Ultrasound In Screening Young Women At High Risk Of Breast Cancer. European Journal of Cancer, 43, pp.1905-17.

McAuley, J., 2004. Hermeneutic understanding. In Cassell, C., Symon, G. (Eds.). Essential Guide to Qualitative Methods in Organizational Research.

Nelson, R.R., Peterhansl, A. \& Sampat, B., 2004. Why And How Innovations Get Adopted: A Tale Of Four Models. Industrial and Corporate Change, 13(5), pp.67999.

Neslin, S.A., 1983. Designing New Outpatient Health Services: Linking Services Features To Subjective Consumer Perceptions. Journal of Health Care Marketing, 3(3), pp.8-21.

NHS Health Unlocked, 2010. NHS.uk. [Online] Available at: http://www.nhs.uk/Conditions/Cancer-of-the-breast-

female/Pages/Screeningbreastcancer\%28female\%29.aspx [Accessed 11 July 2012].

NHSBSP, 2000. Quality Assurance Guidance for Administrative and Clerical Staff. Sheffield: NHS Screening Programmes NHSBSP Publication No 47.

NHSBSP, 2008. Quality Assurance Guidelines for Administrative and Clerical Staff. Sheffield: NHSCSP NHS Cancer Screening Programmes. 
NHSBSP, 2007. Evaluation and Clinical Assessment of the Siemens Novation Full Field Digital Mammography System. Equipment Report. Sheffield: NHSCSP NHSCSP.

NHSBSP, 2010. Guide to implementing the breast screening age extension. NHSBSP Good Practice Guide. Oxford: Cancer Epidemiology Unit NHS.

NHSBSP, 2011. NHS Breast Screening Programme: Annual Review 2011. Annual Review. Sheffield: NHSBSP NHS.

NHSBSP, 2012. Quality Assurance within the NHS Breast Screening Programme. [Online] Available at: http://www.cancerscreening.nhs.uk/breastscreen/qualityassurance.html [Accessed 15 July 2012].

NHSCSP, 2008. Breast and cervical screening: The first 20 years. Sheffield: NHSCSP NHS Cancer Screening Program.

NHSCSP, 2012. Breast Screening Digital Mammography. [Online] Available at: http://www.cancerscreening.nhs.uk/breastscreen/digital-mammography.html [Accessed 16 July 2012].

NHSCSP, 2012. Progress of Mammography Equipment Evaluation. [Online] Available at: http://www.cancerscreening.nhs.uk/breastscreen/publications/progressequip- evaluations.html [Accessed 17 July 2012].

QARC, 2010. NHS Quality Assurance Centre Norht East, Yorkshire, and the Humber. [Online] Available at: http://www.neyhqarc.nhs.uk/BreastScreening/QualityAssuranceoftheNHSBSP .asp x [Accessed 15 July 2012].

Shostack, G.L., 1984. Designing Services That Deliver. Harvard Business Review, January-February, pp.133-39.

Starfield, B., 1998. Primary care: Balancing health needs, services, and technology. New York: Oxford University Press.

Van Steen, G.C. \& Van Tiggelen, R., 2007. Short histroy of mammography: a Belgian Perspective. JBR-BTR, 90, pp.151-53.

WHO, 2012. Cancer Fact Sheet No 297. [Online] Available at: http://www.who.int/mediacentre/factsheets/fs297/en/ [Accessed 15 July 2012]. 